\title{
Catecholaminergic polymorphic ventricular tachycardia
}

\author{
Kaisa Ylänen • Tuija Poutanen • Anita Hiippala • \\ Heikki Swan • Matti Korppi
}

Received: 23 September 2009 / Accepted: 20 January 2010 / Published online: 9 February 2010

(C) Springer-Verlag 2010

\begin{abstract}
Catecholaminergic polymorphic ventricular tachycardia (CPVT) is an inherited arrhythmogenic disorder that causes syncopal episodes related with stress or emotion and even sudden cardiac deaths. Signs and symptoms usually begin in childhood. A suspicion of CPVT should be kept in mind when a child or an adolescent suddenly loses consciousness, particularly if this happens upon physical exercise or sudden mental stress. During the past decade, the knowledge of CPVT genetics and physiology has increased. Exercise testing is essential when suspecting arrhythmogenic origin of syncope, and in the case of CPVT, it may be even more sensitive than Holter monitoring. Beta-antiadrenergic medication can substantially decrease the mortality associated with CPVT. Asymptomatic patients with known CPVT gene defects should also be treated because sudden cardiac death may be the first manifestation of the disease. An implantable cardioverter-defibrillator may also be required in the most severe CPVT cases. In this review, we summarise the current knowledge on the clinical characteristics, diagnostic, genetic and prognostic features of CPVT in children. In all, 133 publications covering 60 years were checked, and those
\end{abstract}

K. Ylänen $(\bowtie) \cdot T$. Poutanen $\cdot$ M. Korppi

Paediatric Research Centre,

Tampere University and University Hospital,

FinMed-3 Building,

33014 Tampere, Finland

e-mail: kaisa@ylanen.fi

\section{A. Hiippala}

Hospital for Children and Adolescents,

Helsinki, Finland

H. Swan

Department of Cardiology, University of Helsinki,

Helsinki, Finland written in English and containing ten or more, mainly paediatric CPVT cases, were included. In addition, a CPVT family with three members and delayed diagnoses until late childhood and adulthood is presented.

Keywords Arrhythmia $\cdot$ Catecholaminergic polymorphic ventricular tachycardia $\cdot$ Childhood $\cdot$ Syncope

\section{Introduction}

Syncopal spell is a common symptom in children. When evaluating its cause, a detailed event history and the observations by the eyewitnesses are often useful. Often, the preceding events and symptoms are compatible with a harmless vasovagal collapse. However, a syncopal spell associated with physical effort should raise a suspicion of a cardiac disorder. If the loss of consciousness is associated with convulsions, it may be misdiagnosed as epilepsy if a prolonged circulatory arrest resulted in brain ischaemia. Most structural heart diseases can be diagnosed or ruled out with echocardiography. A 12-lead electrocardiography (ECG) can reveal an underlying arrhythmogenic disorder such as long QT syndrome (LQTS) or Brugada syndrome [3, 4, 14]. However, a syncopal spell associated with physical exercise or emotional stress may be of arrhythmogenic origin despite normal findings in physical examination, ECG and echocardiography [9].

Catecholaminergic polymorphic ventricular tachycardia (CPVT) is a rare but highly malignant inherited arrhythmia disorder. It is characterised by ventricular tachycardia (VT) which is polymorphic or bidirectional and induced by catecholamines triggered by physical exercise or emotional stress, typically in the absence of a structural heart disease $[1,2,6,8,9,11,12,16,19]$. Sudden cardiac death may be 
the first manifestation of CPVT $[1,19]$. A standard resting ECG is usually normal $[2,6,9,11,16]$. An exercise stress test is essential if CPVT is suspected by symptom history.

For this review, we searched the Ovid Medline database for presumptive CPVT cases using the keyword "catecholaminergic polymorphic ventricular tachycardia", covering the 60-year time period from 1950 to March 2009. In all, 133 hits were obtained. All abstracts were checked, and a total of seven original articles written in English with ten or more CPVT cases, consisting mainly of paediatric patients, were included in the review $[1,2,6,9,11,12,16]$.

\section{Clinical presentation}

Signs and symptoms of CPVT begin usually in childhood (Table 1). They include palpitations, dizziness and even convulsions, and typically, there is a syncopal spell triggered by physical exercise or emotional stress [2, 9, $11,12]$. The mean age of symptom onset has varied from 7 to 9 years, although a later onset has also been reported [1, 2, 6, 9, 11, 16, 19]. Despite the clearly presumptive symptoms, sometimes the diagnosis may be missed or delayed [1, 2, 9, 12]. Many CPVT patients have been considered to have only a vasovagal syncope with no need for further studies $[1,9,12]$, some to have epileptic seizures $[9,11,12]$, and some to have "LQTS with normal QT" $[2,9,12]$ before the diagnosis of CPVT has been made. Approximately $30 \%$ of the patients have a positive family history of stress-related syncope, epileptic seizures or sudden death $[9,10,12]$.

Diagnostic studies and differential diagnosis

A standardised exercise stress test is the most reliable way to diagnose CPVT [2, 6, 11, 16, 19]. Ventricular arrhythmias appear when the sinus rate exceeds an individual threshold rate, usually at a heart rate of $110-130 \mathrm{bpm}[1,2$, $6,9,11,16]$, as summarised in Table 1 . The arrhythmias become more complex when the sinus rate further increases $[9,19]$ and consist of premature ventricular complexes (PVC), couplets, bigeminy and bidirectional or polymorphic VTs, often appearing in this order. When the exercise stress test is discontinued, arrhythmias gradually disappear [9, 19]. These arrhythmias do not usually compromise haemodynamics. Syncope or sudden death in CPVT is a consequence of more rapid or sustained ventricular tachycardia or ventricular fibrillation $[9,11]$. Some CPVT patients may not have arrhythmias in the

Table 1 Summary of the studies published on catecholaminergic polymorphic ventricular tachycardia in children

\begin{tabular}{|c|c|c|c|c|c|c|c|c|c|}
\hline \multirow[t]{2}{*}{ Authors } & \multirow{2}{*}{$\begin{array}{l}\text { Number of } \\
\text { patients } \\
\text { (female/ } \\
\text { male) }\end{array}$} & \multirow{2}{*}{$\begin{array}{l}\text { Age at } \\
\text { onset } \\
\left(\text { years) }^{a}\right.\end{array}$} & \multirow{2}{*}{$\begin{array}{l}\text { Age at } \\
\text { diagnosis } \\
\text { (years) }^{\mathrm{a}}\end{array}$} & \multirow{2}{*}{$\begin{array}{l}\text { Follow- } \\
\text { up time } \\
\text { (years) }^{\mathrm{a}}\end{array}$} & \multirow{2}{*}{$\begin{array}{l}\text { Heart } \\
\text { rate at } \\
\text { rest } \\
(\mathrm{bpm})^{\mathrm{a}}\end{array}$} & \multicolumn{2}{|c|}{ Threshold frequency (bpm) ${ }^{\mathrm{a}}$} & \multirow{2}{*}{$\begin{array}{l}\text { Mortality } \\
\text { among the } \\
\text { probands }\end{array}$} & \multirow{2}{*}{$\begin{array}{l}\text { Genetic } \\
\text { defect }\end{array}$} \\
\hline & & & & & & $\begin{array}{l}\text { Onset of } \\
\text { ventricular } \\
\text { premature } \\
\text { complexes }\end{array}$ & $\begin{array}{l}\text { Onset of } \\
\text { ventricular } \\
\text { tachycardia }\end{array}$ & & \\
\hline $\begin{array}{l}\text { Leenhardt } \\
\text { et al. } \\
1995\end{array}$ & $219 / 12$ & $3-16$ & $3.5-16.5$ & $2-16$ & $42-75$ & $105-150$ & NA & $2 / 21$ & NA \\
\hline $\begin{array}{l}\text { Lahat et } \\
\text { al. } 2001\end{array}$ & $139 / 4$ & $3.5-12$ & $0.25-25$ & 1.5 & $47-90$ & $90-123$ & $90-123$ & 0 & $\begin{array}{l}\text { Chromosome } \\
\text { 1p13-21 } \\
\text { (recessive) }\end{array}$ \\
\hline $\begin{array}{l}\text { Priori et } \\
\text { al. } 2002^{\mathrm{c}}\end{array}$ & $3017 / 13$ & $2-38$ & $15 \pm 10$ & $4 \pm 2.5$ & NA & NA & NA & NA & $\begin{array}{r}\text { RyR2 gene } \\
\text { mutations }\end{array}$ \\
\hline $\begin{array}{l}\text { Sumitomo } \\
\text { et al. } \\
2003\end{array}$ & $29(16 / 13)$ & $2-30$ & NA & $6.8 \pm 4.9$ & $59 \pm 11$ & NA & $79-214$ & $7 / 29$ & NA \\
\hline $\begin{array}{l}\text { Allouis et } \\
\text { al. } 2005\end{array}$ & $11(9 / 2)$ & $6-27$ & 5-39 & NA & NA & $110-160$ & NA & $2 / 11$ & $\begin{array}{l}\text { RyR2 gene } \\
\text { mutation }\end{array}$ \\
\hline $\begin{array}{l}\text { Postma et } \\
\text { al. } 2005^{\mathrm{c}}\end{array}$ & $12(9 / 3)$ & $4-51$ & NA & $2-28$ & $43-73$ & NA & $90-150$ & $1 / 12$ & $\begin{array}{r}R y R 2 \text { gene } \\
\text { mutations }\end{array}$ \\
\hline $\begin{array}{r}\text { Celiker et } \\
\text { al. } 2009\end{array}$ & $165 / 11$ & $4.5-12$ & $5-15$ & $1-9$ & $45-60$ & $70-140$ & $115-160$ & $4 / 16$ & $\begin{array}{l}R y R 2 \text { gene } \\
\text { mutation }^{\mathrm{d}}\end{array}$ \\
\hline
\end{tabular}

NA not available

${ }^{\text {a }}$ Mean or ranges

${ }^{\mathrm{b}} \mathrm{CASQ2}$ gene mutation was later found in chromosome 1p13-21 [7]

${ }^{\mathrm{c}}$ Priori and Postma expanded their studies from the original probands also to their families, but only the original probands are included

${ }^{\mathrm{d}}$ Verified in one child who experienced a sudden death. Genetic studies of the others are incomplete 
exercise stress test during early childhood, but the change in the phenotype occurs later in life [17, 19]. Therefore, a regular follow-up with repeated exercise stress tests is indicated, e.g. for younger siblings of a CPVT patient. Progressive ventricular arrhythmias may also be provoked in some cases by intravenous infusion of catecholamines like adrenaline $[2,6,9,12,16]$. Echocardiography is needed to exclude structural heart disease, e.g. tumours of the heart, coronary anomalies or different cardiomyopathies, which do not present with murmurs. For the CPVT diagnosis, electrolyte abnormalities should be excluded, as well as the use of any drugs known to trigger arrhythmias. The 24-h Holter monitoring may reveal arrhythmias typical for CPVT if the sinus rate of the patient exceeds the individual arrhythmia-inducing threshold during monitoring. The 24-h Holter monitoring can be very useful in young, physically active children who are not yet able to perform exercise stress test. Symptoms and findings in CPVT are summarised in Table 2.

Other inherited arrhythmogenic cardiac disorders that can cause malignant ventricular tachyarrhythmias should also be excluded. The clinical characteristics and the typical resting ECG findings in the common inherited arrhythmogenic cardiac disorders are presented in Table 3. Exerciseinduced, highly reproducible polymorphic VT is one of the diagnostic criteria of CPVT. The 12-lead resting ECG is usually within normal limits, though a relative sinus bradycardia or prominent $U$ waves may be seen as nonspecific findings $[2,6,9,11,16]$. CPVT patients may have a slight prolongation of the corrected QT interval in the resting ECG, however not exceeding $470 \mathrm{~ms}$ [19], and there is no prolongation of the QT interval during exercise $[12,16]$. In the patients with LQTS, the corrected QT interval is usually more than $460 \mathrm{~ms}$, and they develop arrhythmias during exercise stress test infrequently [4]. The corrected QT interval shorter than $320 \mathrm{~ms}$ raises a suspicion of the short QT syndrome [15]. Exercise-provoked arrhythmias may develop also in arrhythmogenic right ventricular dysplasia/cardiomyopathy (ARVD/C), but the typical ECG pattern of $\mathrm{ARVD} / \mathrm{C}$ and the structural abnormalities of the right ventricule separate $\mathrm{ARVD} / \mathrm{C}$ from CPVT [19]. The typical arrhythmia in ARVD/C is the monomorphic VT with left bundle branch block pattern that is clearly different from the polymorphic PVCs or VT in CPVT. Patients with Brugada syndrome do not manifest polymorphic PVCs upon physical effort either, and the absence of the right bundle branch block and the ST segment elevations in the precordial ECG leads after provocation testing with sodium channel blocking agent, e.g. flecainide, make Brugada syndrome very unlikely $[3,14]$. Arrhythmias in Brugada syndrome appear usually at rest or during sleep $[3,14]$.

\section{Genetic abnormalities}

CPVT can be inherited either in an autosomal dominant (CPVT1) or recessive (CPVT2) way. The more common type 1 CPVT (MIM\#604772) is caused by mutations in the cardiac ryanodine receptor gene $R y R 2$ on chromosome

Table 2 Symptoms and findings in catecholaminergic polymorphic ventricular tachycardia

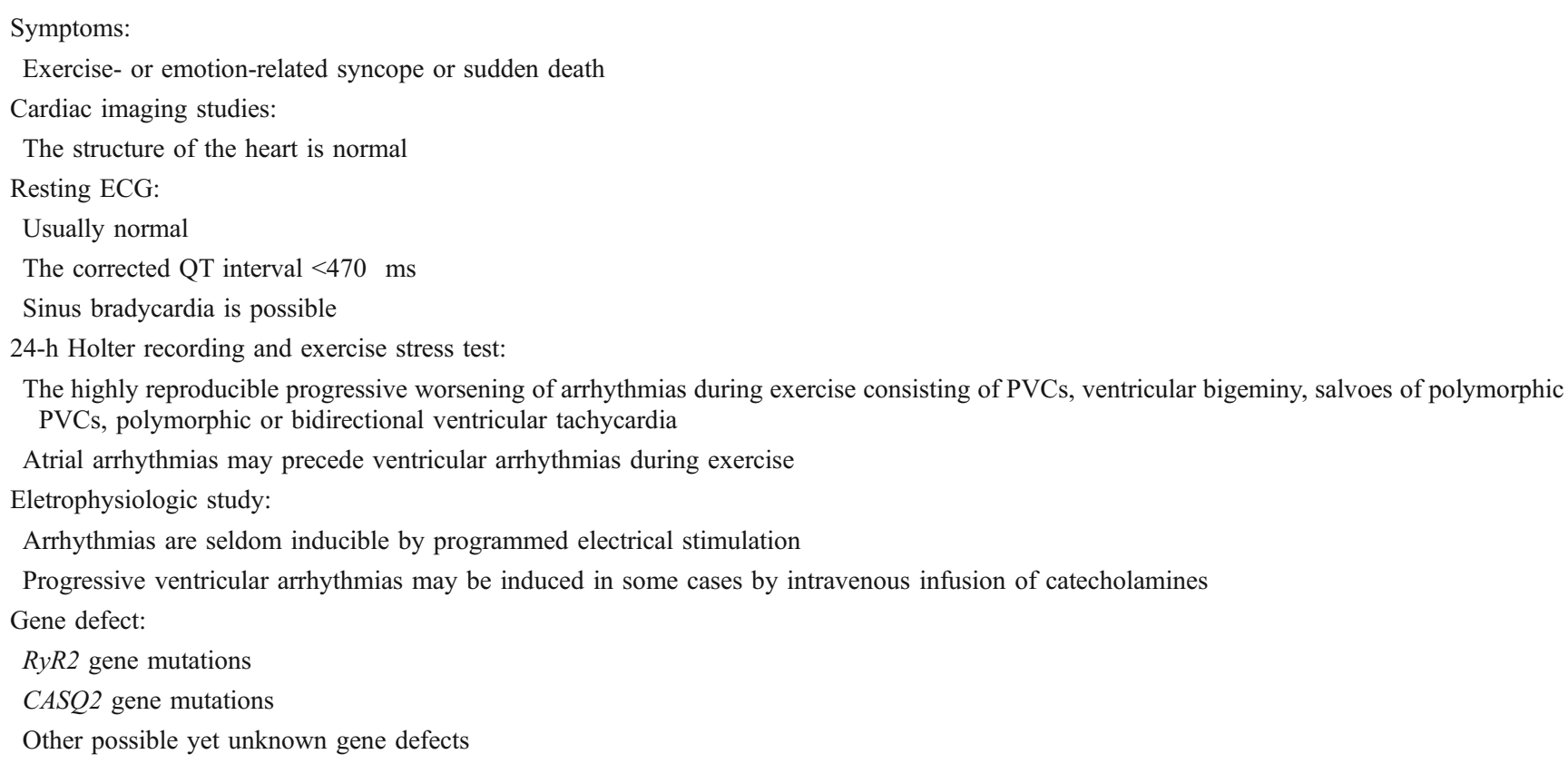

PVCs premature ventricular complex 
Table 3 Inherited arrhythmogenic cardiac disorders causing malignant ventricular tachyarrhythmias

\begin{tabular}{|c|c|c|}
\hline Disorder & $\begin{array}{l}\text { Typical findings in the } \\
\text { resting ECG }\end{array}$ & Clinical presentation \\
\hline $\begin{array}{l}\text { Catecholaminergic polymorphic } \\
\text { ventricular tachycardia (CPVT) }\end{array}$ & Normal & $\begin{array}{l}\text { Multifocal premature ventricular complexes and polymorphic } \\
\text { ventricular tachycardia during exercise or emotional stress }\end{array}$ \\
\hline Long QT syndrome (LQTS) & $\begin{array}{l}\text { Prolongation of the OTc } \\
\text { interval }(>460 \mathrm{~ms}) \\
\text { Abnormal T-wave } \\
\text { morphology }\end{array}$ & $\begin{array}{l}\text { Arrhythmias associated with physical or emotional stress, sudden } \\
\text { arousal or sleep }\end{array}$ \\
\hline Brugada syndrome & $\begin{array}{l}\text { ST elevation in the right } \\
\text { precordial leads } \\
\text { RBBB }\end{array}$ & Arrhythmias occurring at rest or during sleep \\
\hline $\begin{array}{l}\text { Arrhythmogenic right ventricular } \\
\text { dysplasia/cardiomyopathy (ARVD/C) }\end{array}$ & $\begin{array}{l}\text { T-wave inversion in the } \\
\text { right precordial leads } \\
\text { Epsilon waves }\end{array}$ & $\begin{array}{l}\text { Arrhytmias during exercise } \\
\text { LBBB pattern during tachycardia } \\
\text { Structural abnormalities of the right ventricle }\end{array}$ \\
\hline Short QT syndrome & $\begin{array}{l}\text { Short QTc interval } \\
(<320 \mathrm{~ms})\end{array}$ & Very rare \\
\hline Hypertrophic cardiomyopathy & $\begin{array}{l}\text { LVH } \\
\text { T-wave inversion }\end{array}$ & $\begin{array}{l}\text { Outflow tract murmur due to hypertrophy of the left ventricle } \\
\text { Syncope }\end{array}$ \\
\hline Dilated cardiomyopathy & $\begin{array}{l}\mathrm{LVH} \\
\text { Conduction disturbances }\end{array}$ & Cardiac insufficiency due to dilatation of the left ventricle \\
\hline
\end{tabular}

$R B B B$, right bundle branch block, $L B B B$ left bundle branch block, $L V H$ left ventricular hypertrophy

1q42-q43 and is a consequence of a defective calcium release from sarcoplasmic reticulum [8, 13, 19]. In the autosomal recessive variant, type 2 CPVT (MIM\#611938), the causative gene, is the cardiac calsequestrin gene CASQ2 located on chromosome 1p13-21 [6, 7]. CASQ2 is a calcium buffering protein that has an active role in the control of calcium release from sarcoplasmic reticulum to cytosol. To date, there are over 70 known mutations in $R y R 2$ gene and seven known mutations in CASQ2 gene associated with CPVT (more information is available online at http//www.fsm.it/cardmoc/). Mutations in the $R y R 2$ gene have been identified in around $50 \%$ and those in the CASQ2 gene in $<2 \%$ of patients with CPVT $[5,12]$. Other yet unknown CPVT genes are likely to exist. In the study of Priori et al. [12], $90 \%$ of patients with non-genotyped CPVT were women and they became symptomatic in adulthood, at 20 (mean) \pm 12 (SD) years of age, whereas the respective age was 8 (mean) \pm 2 (SD) years in the RyR2-associated CPVT cases.

\section{Therapy and prognosis}

The cumulative mortality of the untreated CPVT cases is $30-50 \%$ by the age of $20-30$ years $[8,9,19]$. Because of the poor prognosis of untreated CPVT, drug therapy is indicated for all clinically diagnosed patients and usually also for all silent carriers of a $R y R 2$ mutation [20]. According to the current knowledge, beta-antiadrenergic medication is the drug of choice $[2,9,16]$, and a maximal tolerated dose should be used. An implantable cardioverterdefibrillator is indicated for those patients who experience cardiac arrest, sustained VT or syncopal spell despite an adequate beta-blocker therapy [20]. Regular medication is of uttermost importance because missing even a single dose may lead to arrhythmias and increase the risk of sudden death [9]. Exercise stress test and Holter monitoring may help in finding the adequate dosage of the betaantiadrenergic medication to control arrhythmias. It should be noted, though, that the absence of exercise-provoked arrhythmias does not completely exclude the risk of more severe arrhythmias. The aim of the medication is to avoid the heart rate exceeding the threshold heart rate for CPVT, and some studies have reported an almost complete prevention of cardiac events during beta-antiadrenergic medication [6, 11, 19]. However, other studies have reported a high recurrence rate of symptoms and even sudden death despite medication $[2,12,16]$. Calcium channel antagonists in combination with betaantiadrenergic medication have been shown to significantly reduce the exercise-provoked ventricular arrhythmias in CPVT patients [18], but their impact in prognosis is not known.

\section{Family report}

A previously healthy 13-year-old boy fell unconscious whilst playing baseball at school. The onset was sudden, 
not associated with any preceding symptoms but evidently associated with a short intensive running. Unconsciousness lasted about a minute, and some convulsive movements were observed in the legs. The boy recovered spontaneously and completely. There was no known preceding trauma, infection or intoxication. A few years earlier, the boy had experienced a near-drowning situation whilst swimming, but had managed to get up from the water. $\mathrm{He}$ had also felt occasional chest palpitations. In the emergency room, the patient was in good general condition. The clinical neurologic and cardiologic status was normal. The blood pressure was $116 / 70 \mathrm{mmHg}$, and the transcutaneous oxygen saturation was $98 \%$. The basic laboratory tests as well as the chest X-ray and the electroencephalogram were all normal. The patient was monitored at an acute paediatric ward for 2 days, and no syncope, convulsions or arrhythmias occurred. The 12-lead ECG showed sinus rhythm with $56 \mathrm{bpm}$, and the corrected QT interval was normal (380 ms). The 24-h Holter recording revealed sinus rhythm between 40 and $113 \mathrm{bpm}$, and there were neither ectopic beats nor arrhythmias. The structure and the function of the heart were found to be normal on echocardiography.
The ECG during exercise stress test revealed multifocal PVCs when the sinus rate exceeded $130 \mathrm{bpm}$, followed by ventricular bigeminy and ventricular couplets (Fig. 1). After cessation of exercise, PVCs disappeared. Neither prolongation of the QT interval nor any ST-T changes were observed during the exercise stress test. The findings of the exercise ECG were diagnostic for CPVT. The magnetic resonance imaging of the heart confirmed the normal cardiac structures including the right ventricular outflow tract.

The family history indicated that the father of the patient had died suddenly in his 40 s due to myocardial infarction, but there were no other known cases with heart disorders or sudden death. The patient's mother was on continuous medication for epilepsy. Her first syncopal episode had occurred at the age of 12 years, and the episodes appeared only during physical exercise or emotional stress. In the exercise ECG, the mother had over 400 multifocal PVCs starting at the heart rate of $118 \mathrm{bpm}$ and a short ventricular tachycardia with four consecutive PVCs (Fig. 2). The 16year-old sister of the patient had suffered from a few syncopal episodes, which were considered to be harmless vasovagal events. The exercise ECG of the sister revealed
Fig. 1 The chest lead electrocardiograms V1-V6 during exercise stress test of the index patient showing multifocal PVCs, bigeminy and a couplet

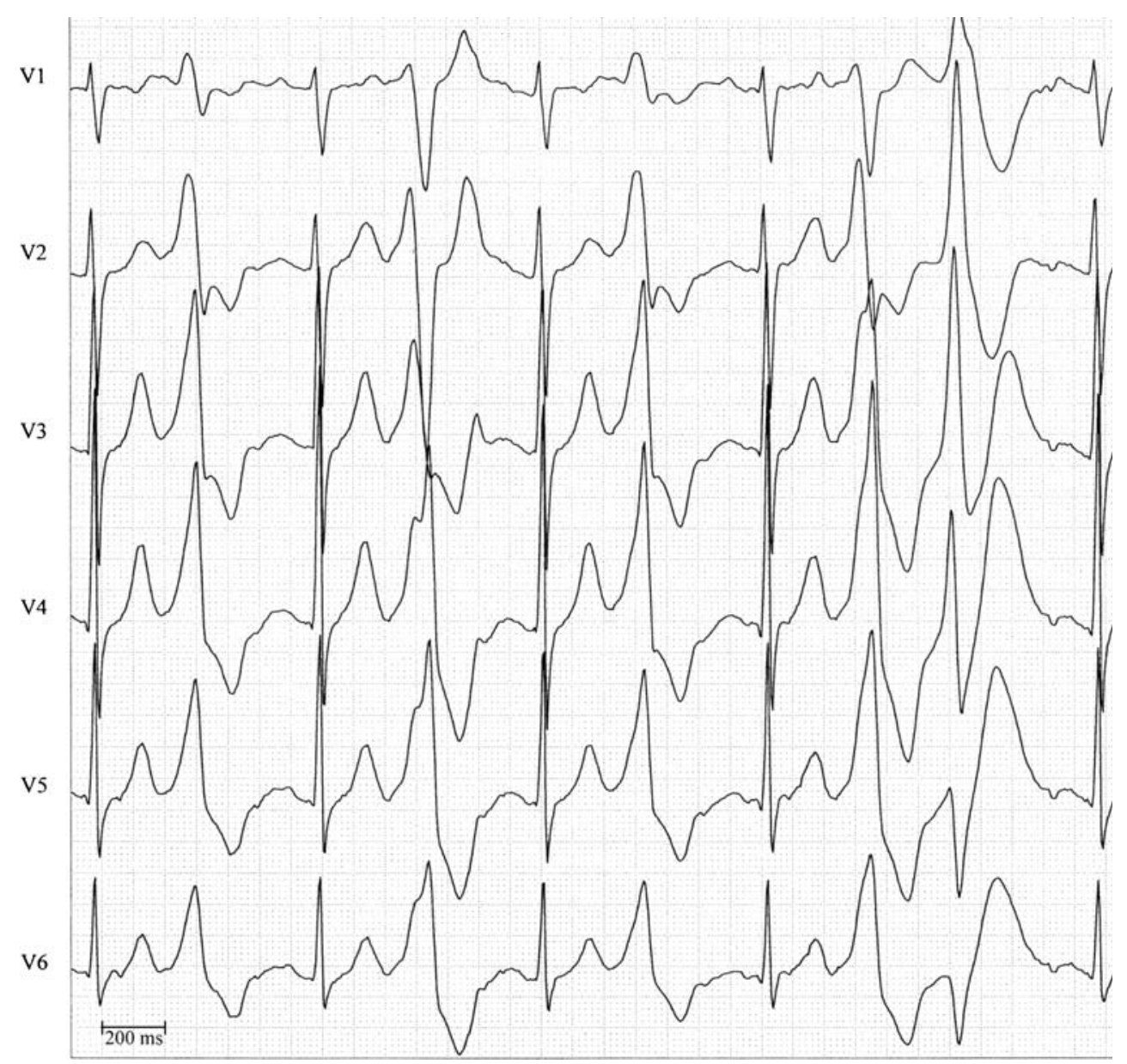


Fig. 2 The 12-lead ECG during exercise stress test of the mother of the index patient at workload $105 \mathrm{~W}$, before beta-

antiadrenergic medication, showing multifocal PVCs, bigeminy and couplets

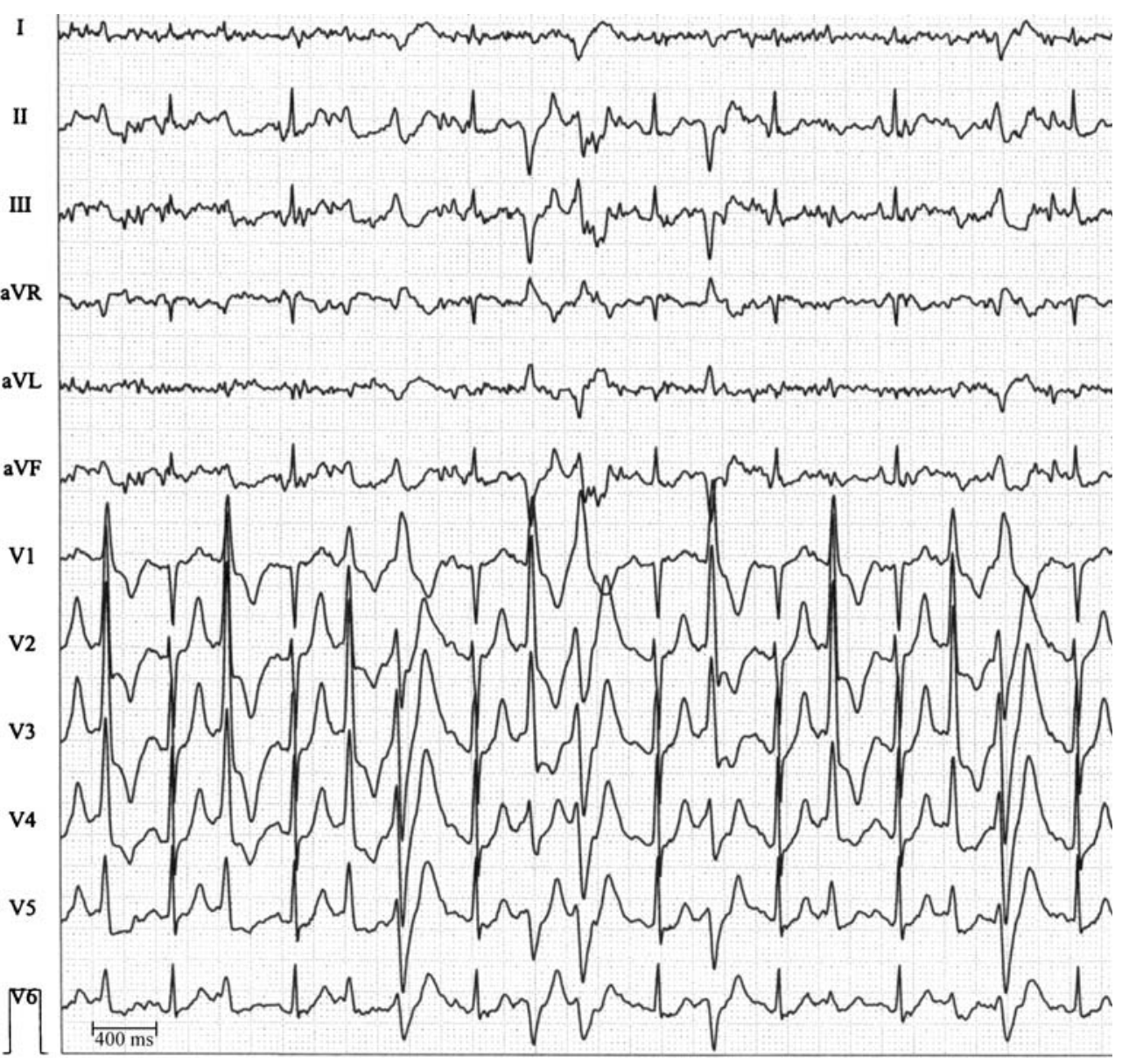

Fig. 3 The chest lead electrocardiogram V2 during exercise stress test of the mother of the index patient at workload $105 \mathrm{~W}$ during beta-antiadrenergic medication. Indicator arrhythmias have not disappeared, but the heart rate has decreased showing a response to beta-antiadrenergic medication

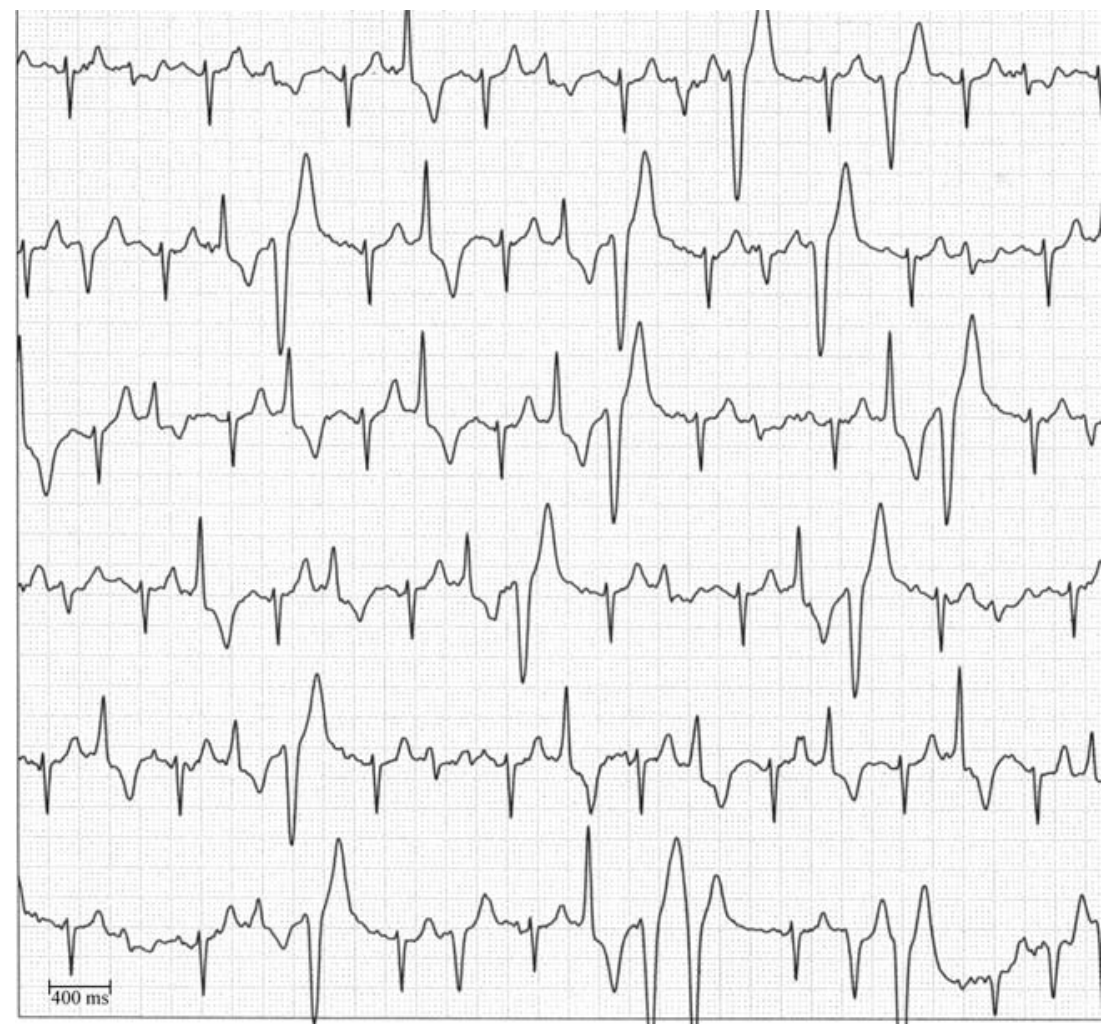


over 160 predominantly single PVCs but also couplets, which started at a heart rate of $140 \mathrm{bpm}$. The antiepileptic medication of the mother was discontinued, and betablocker therapy was started both for the mother and the sister (Fig. 3).

The index patient was treated with a beta-blocker, bisoprolol, at a dosage of $0.2 \mathrm{mg} \mathrm{kg}^{-1} \mathrm{day}^{-1}$. The aim of the medication was to prevent the heart rate from exceeding $130 \mathrm{bpm}$. The efficacy of beta-blocker therapy was confirmed by serial exercise stress tests and 24$\mathrm{h}$ Holter recordings. In the Holter recordings, the mean heart rate stayed between 55 and 73 bpm also during physical activities. In the exercise stress tests, the maximal heart rate decreased from $184 \mathrm{bpm}$ before medication to $122 \mathrm{bpm}$ during medication, showing a good response to beta-blocker therapy. Competitive sports demanding vigorous physical exercise were prohibited. During a 2-year follow-up on medication, no syncopal episodes have occurred. Clustering of CPVT in the family suggests a dominant inheritance. The $R y R 2$ gene analysis is in progress

\section{Conclusion}

CPVT is an inherited cardiac arrhythmic disorder showing a malignant clinical course in the absence of structural defects in the heart. The mortality rate is high and a sudden death may occur in an otherwise healthy child or adolescent. The patients experience ventricular arrhythmias with modest exercise, emotional stress or exposure to catecholamines. In addition to the typical clinical picture, there are also reports of atypical CPVT cases with paroxysmal atrial fibrillation [10] or sudden deaths during sleep [1].

Diagnosing CPVT can be difficult especially in young children. When presumptive symptoms are encountered, an exercise ECG and Holter monitoring should be performed since CPVT cannot be diagnosed by a resting ECG or other cardiologic studies. Sometimes, the exercise-provoked arrhythmias can be demonstrated only after a delay of months or more after the first syncopal episode has occurred, emphasising the necessity of repeated exercise stress tests when there is a high suspicion of CPVT. In the case of a new CPVT diagnosis, it is essential to expand the evaluation to the rest of the family too to find other potential CPVT patients. Screening of family members by genetic testing is possible in the case of a known gene mutation. In most CPVT cases, symptoms can be prevented with beta-antiadrenergic medication. Drug treatment is indicated in all CPVT cases, including non-symptomatic patients diagnosed with a CPVT gene defect.
Conflict of interest There is no conflict of interest.

\section{References}

1. Allouis M, Probst V, Jaafar P et al (2005) Unusual clinical presentation in a family with catecholaminergic polymorphic ventricular tachycardia due to a G14876A ryanodine receptor gene mutation. Am J Cardiol 95:700-702. doi:10.1016/j. amjcard.2004.10.057

2. Celiker A, Erdogan I, Karagöz T et al (2009) Clinical experiences of patients with catecholaminergic polymorphic ventricular tachycardia. Cardiol Young 19:45-52. doi:10.1017/ S1047951108003338

3. Chen PS, Priori SG (2008) The Brugada syndrome. J Am Coll Cardiol 12:1176-1180. doi:10.1016/j.jacc.2007.12.006

4. Goldenberg I, Zareba W, Moss AJ (2008) Long QT syndrome. Curr Probl Cardiol 33:629-694. doi:10.1016/j.cpcardiol.2008.07.002

5. Katz G, Arad M, Eldar M (2009) Catecholaminergic polymorphic ventricular tachycardia from bedside to bench and beyond. Curr Probl Cardiol 34:9-43. doi:10.1016/j. cpcardiol.2008.09.002

6. Lahat H, Eldar M, Levy-Nissenbaum E et al (2001) Autosomal recessive catecholamine- or exercise-induced polymorphic ventricular tachycardia: clinical features and assignment of the disease gene to chromosome 1p13-21. Circulation 103:2822-2827

7. Lahat H, Pras E, Olender T et al (2001) A missense mutation in a highly conserved region of CASQ2 is associated with autosomal recessive catecholamine-induced polymorphic ventricular tachycardia in Bedouin families from Israel. Am J Hum Genet 69:1378-1384

8. Laitinen PJ, Brown KM, Piippo K et al (2001) Mutations of the cardiac ryanodine receptor $(R y R 2)$ gene in familial polymorphic ventricular tachycardia. Circulation 103:485-490

9. Leenhardt A, Lucet V, Denjoy I et al (1995) Catecholaminergic polymorphic ventricular tachycardia in children. A 7-year followup of 21 patients. Circulation 91:1512-1519

10. Marjamaa A, Laitinen-Forsblom P, Lahtinen AM et al (2009) Search for cardiac calcium cycling gene mutations in familial ventricular arrhythmias resembling catecholaminergic polymorphic ventricular tachycardia. BMC Med Genet 10:12. doi:10.1186/1471-2350-10-12

11. Postma AV, Denjoy I, Kamblock J et al (2005) Catecholaminergic polymorphic ventricular tachycardia: $R y R 2$ mutations, bradycardia and follow up of the patients. J Med Genet 42:863-870. doi:10.1136/jmg.2004.028993

12. Priori SG, Napolitano C, Memmi M et al (2002) Clinical and molecular characterization of patients with catecholaminergic polymorphic ventricular tachycardia. Circulation 106:69-74. doi:10.1016/j.jacc.2007.12.006

13. Priori SG, Napolitano C, Tiso N et al (2001) Mutations in the cardiac ryanodine receptor gene $(h R y R 2)$ underlie catecholaminergic polymorphic ventricular tachycardia. Circulation 103:196-200

14. Probst V, Denjoy I, Meregalli PG et al (2007) Clinical aspects and prognosis of Brugada syndrome in children. Circulation 115:2042-2048. doi:10.1161/CIRCULATIONAHA.106.664219

15. Schimpf R, Wolpert C, Gaita F et al (2005) Short QT syndrome. Cardiovase Res 67:357-366. doi:10.1016/j.cardiores.2005.03.026

16. Sumitomo N, Harada K, Nagashima M et al (2003) Catecholaminergic polymorphic ventricular tachycardia: electrocardiographic characteristics and optimal therapeutic strategies to prevent sudden death. Heart 89:66-70. doi:10.1136/ heart.89.1.66 
17. Swan H, Laitinen PJ (2002) Familial polymorphic ventricular tachycardia - intracellular calcium channel disorder. Card Electrophysiol Rev 6:81-87

18. Swan H, Laitinen P, Kontula K et al (2005) Calcium channel antagonism reduces exercise-induced ventricular arrhythmias in catecholaminergic polymorphic ventricular tachycardia patients with RyR2 mutations. J Cardiovasc Electrophysiol 16:162-166. doi:10.1046/j.1540-8167.2005.40516.x

19. Swan H, Piippo K, Viitasalo M et al (1999) Arrhythmic disorder mapped to chromosome 1q42-q43 causes malignant polymorphic ventricular tachycardia in structurally normal hearts. J Am Coll Cardiol 34:2035-2042

20. Zipes DP, Camm AJ, Borggrefe $M$ et al (2009) ACC/AHA/ ESC 2006 guidelines for management of patients with ventricular arrhythmias and the prevention of sudden cardiac death: a report of the American College of Cardiology/ American Heart Association Task Force and the European Society of Cardiology Committee for Practice Guidelines. Circulation 114:e385-e484. doi:10.1161/CIRCULATION AHA.106.178233 